\title{
Addition of Glucose to Dolichyl Diphosphate Oligosaccharide and Transfer to Protein
}

\author{
Roberto J. STANELONI, Rodolfo A. UGALDE, and Luis F. LELOIR \\ Instituto de Investigaciones Bioquimicas "Fundación Campomar" and Facultad de Ciencias Exactas y Naturales, Buenos Aires
}

(Received August 31, 1979)

The glycosylation of asparagine residues in proteins is known to occur by transfer from a dolichyl diphosphate oligosaccharide containing glucose. Paper chromatography allowed the separation of oligosaccharides (obtained by acid hydrolysis of the dolichyl diphosphate derivative) containing 1 , 2 and 3 glucose residues. Using this procedure it was found that the addition of all three glucoses to the dolichyl diphosphate oligosaccharide occur with dolichyl phosphate glucose as donor. Furthermore only the compound with three glucoses was used as donor in the transfer to protein. The addition of glucose to exogenous dolichyldiphosphate oligosaccharide labelled by transfer from radioactive guanosine diphosphate mannose was detected.

There is evidence showing that the donor for the glycosylation of asparagine residues in proteins is a dolichyl diphosphate oligosaccharide [1-2]. The evidence shows that this oligosaccharide, whose structure is known [3], is built up by the transfer of acetylglucosamine phosphate to dolichyl phosphate followed by the addition of one more acetylglucosamine, nine mannoses and one to three glucoses. The oligosaccharide is then transferred to protein and the glucose residues are removed. The complex oligosaccharides may then be formed by removal of six mannoses and addition of acetylglucosamine, galactose and sialic acid. Another pathway consisting in removal or addition of mannose residues would lead to the formation of the high-mannose-type oligosaccharides.

This paper reports studies on some aspects of the process of glucose addition to the oligosaccharide and of transfer of the latter to protein.

\section{MATERIALS AND METHODS}

Rat liver microsomes were prepared as described previously [4]. Dol- $P$ was isolated and purified up to the DEAE-cellulose step [5]. Dol- $P-\left[{ }^{14} \mathrm{C}\right] \mathrm{Glc}$ was prepared by incubation of UDP- $\left[{ }^{14} \mathrm{C}\right] \mathrm{Glc}$ with liver microsomes and purified by DEAE-cellulose chromatography $[5,6]$. Dol-P-P-Glc-oligosaccharide labelled in the glucose or in the mannose was obtained by incubation of microsomes with UDP- $\left[{ }^{14} \mathrm{C}\right] \mathrm{Glc}[7]$

\footnotetext{
Abbreviations. The glucose-containing oligosaccharides with three, two and one glucose residues are referred to as $\mathrm{Glc}_{3}, \mathrm{Glc}_{2}$ and Glc $_{1}$ oligosaccharides. Dol, dolichyl; Gle, glucose; Man, mannose; $P$, phosphate.
}

or GDP- $\left[{ }^{14} \mathrm{C}\right] \mathrm{Man}[8]$ respectively. Dol- $P$ - $P$-Glc-oligosaccharide labelled in mannose and glucose was obtained from oviduct slices incubated with $\left[{ }^{14} \mathrm{C}\right]-\mathrm{man}-$ nose $[9,10]$. Free oligosaccharides were obtained from the dolichyl diphosphate derivatives by mild acid hydrolysis [10].

Paper chromatography of the oligosaccharides was carried out with the following solvent: 1-propanol/ nitromethane/water $(5: 2: 4)$. This mixture is referred to as the propanol-nitromethane solvent.

\section{RESULTS}

Preparation of Dolichyl-Diphosphate-Glucose-Containing Oligosaccharides. Incubation of UDP- $\left[{ }^{14} \mathrm{C}\right] \mathrm{Glc}$ with liver microsomes leads to the formation of labelled Dol- $P-P$ oligosaccharides. Mild acid hydrolysis of these compounds results in the liberation of free oligosaccharides which can be separated by paper chromatography into three different compounds. This separation was first obtained by Kornfeld et al. [11] with 1 -butanol/pyridine/water $(4: 3: 4)$ as solvent in a 16-day run. With the propanol/nitromethane solvent the separation can be obtained in 7 days (Fig. 1).

The relative amounts of the different glucosecontaining oligosaccharides vary with the conditions used for the synthesis. The changes at various incubation times are shown in Fig. 2. The Glc -oligosaccharide $_{3}$ increases up to $20 \mathrm{~min}$ and then decreases progressively. The Glc $_{2}$-oligosaccharide follows a similar course but does not decrease as fast while $\mathrm{Glc}_{1}$-oligosaccharide remains constant. When $\mathrm{Glc}_{1}$ and $\mathrm{Glc}_{2}$ oligosaccharides had to be prepared an incubation time of $80 \mathrm{~min}$ was used. Under these conditions separation by paper 


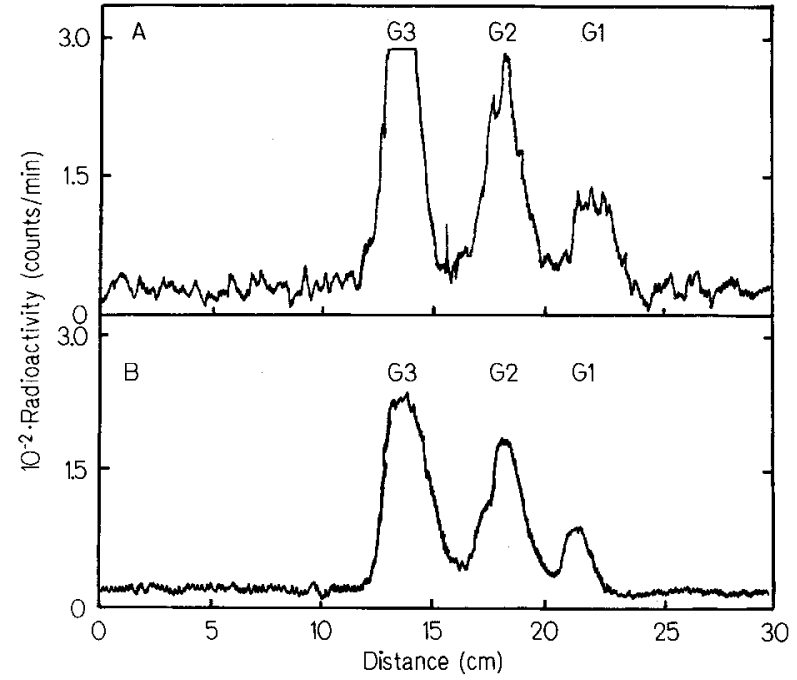

Fig. 1. Paper chromatography of the glucose-containing oligosaccharides. The compounds labelled in the glucose were obtained as described in [7]. (A) 1-Propanol-nitromethane solvent for 7 days. (B) $1-$ Butanol/pyridine/water $(4: 3: 4)$ for 20 days

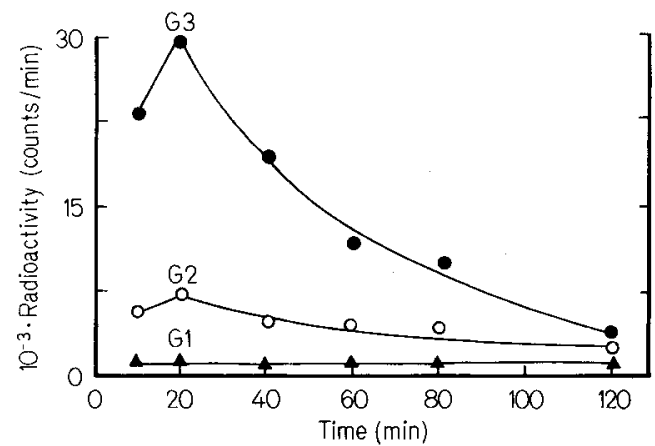

Fig. 2. Changes in the different glucose-containing oligosaccharide at different incubation times. The incubation mixture contained: $0.1 \mathrm{M}$ Tris-maleate $\mathrm{pH} 7.7,0.01 \mathrm{M} \mathrm{Mg-EDTA}, 0.01 \mathrm{M} \mathrm{MgCl}_{2}$, $0.02 \mathrm{M}$ 2-mercaptoethanol, liver microsomes (about $10 \mathrm{mg}$ of protein), and 300000 counts/min of UDP- $\left[{ }^{14} \mathrm{C}\right]$ glucose $(268 \mathrm{Ci} /$ $\mathrm{mol}$ ). Final volume $250 \mu \mathrm{l}$. The reaction mixture was incubated for the indicated times at $30^{\circ} \mathrm{C}$. Methanol $(2 \mathrm{ml}), \mathrm{MgCl}_{2} 4 \mathrm{mM}(0.75 \mathrm{ml})$ and chloroform $(3.0 \mathrm{ml})$ were then added and the isolation of Dol-P-P-Glc-oligosaccharides was carried out as described previously [6]. The glucose-containing oligosaccharides obtained by mild acid hydrolysis were chromatographed with propanol/nitromethane solvent for 7 days. The radioactive peaks were located with a scanner and the corresponding pieces of paper were counted with a toluene-based scintillation fluid, in a scintillation counter

chromatography was better because the amount of Glc $_{3}$-oligosaccharide was lower. The decrease in glucose-containing oligosaccharides is brought about by the glucosidases present in the microsome fraction [12] but a part may be due to transfer to protein.

Chromatography of a Glucose-Containing Oligosaccharide Labelled in Glucose and Mannose. Chromatography with the propanol-nitromethane solvent has allowed the separation of some products which were thought to be homogenous. Preparations of glucosecontaining oligosaccharide obtained from tissue slices incubated with radioactive glucose or mannose gave only one peak when chromatographed on paper $[10$, 13]. A similar preparation has now been found to contain four substances when analyzed under the new conditions (Fig. 3). Information on their identity was obtained using specific liver microsomal glucosidases separated by gel filtration [14]. The substance of peak $\mathrm{G}_{3}$ when treated with the glucosidase specific for $\mathrm{Glc}_{3}$ oligosaccharide yielded glucose and a product that chromatographed like $\mathrm{G}_{2}$. When the substance of peak $G_{2}$ was treated with the glucosidase that acts on $\mathrm{Glc}_{2}$ and $\mathrm{Glc}_{1}$ oligosaccharides the products were glucose and a substance which ran like peak $G_{0}$ in Fig. 3 which was probably the glucose-free oligosaccharide. A substance with a similar mobility was obtained on incubation of microsomes with GDP. $\left[{ }^{14} \mathrm{C}\right] \mathrm{Man}$.

Transfer from Dolichyl Monophosphate Glucose. Although it was shown some time ago [6] that Dol$P$-Glc can serve as donor for the formation of Dol$P-P$ oligosaccharide it had not been established whether all the glucoses are transferred by that mechanism. There remained the possibility that some glucoses could be transferred directly from UDP-Glc or some other donor. To decide this point, labelled Dol$P$-Glc was incubated with liver microsomes and the Dol- $P$ - $P$-Glc-oligosaccharide formed was hydrolysed and the oligosaccharides were chromatographed as described before. Fig. 4 shows that the three compounds became labelled. These compounds had the mobility in paper chromatography, with 1-butanol/ pyridine/water $(4: 3: 4)$, corresponding to $\mathrm{Glc}_{3}, \mathrm{Glc}_{2}$ and $\mathrm{Glc}_{1}$ oligosaccharides. Treatment of peak $\mathrm{G}_{3}$ after elution from the paper with a glucosidase specific for $\mathrm{Glc}_{3}$-oligosaccharide [14] led to the liberation of radioactive glucose. The substances from peak $G_{2}$ or $\mathrm{G}_{1}$ also yielded glucose when treated with a glucosidase specific for $\mathrm{Glc}_{2}$ and $\mathrm{Glc}_{1}$ oligosaccharides.

The fact that the three glucose-containing oligosaccharides were labelled indicates that their glucoses were transferred directly from Dol- $P$-Glc.

Transfer to Protein. Previous work showed that Dol- $P$ - $P$-Glc-oligosaccharides are transferred faster to endogenous protein than glucose-free compounds [15]. However, it was not established which of the glucose-containing oligosaccharides was transferred. A Dol- $P$ - $P$-Glc-oligosaccharide preparation containing the $\mathrm{Glc}_{1}, \mathrm{Glc}_{2}$ and $\mathrm{Glc}_{3}$ components was incubated with liver microsomes with and without $\mathrm{Mn}^{2+}$ ions which are known to be required for transfer to protein. The Dol-P-P-Glc-oligosaccharides were then extracted, hydrolysed and chromatographed on paper. As shown in Fig. 5 in the presence of $\mathrm{Mn}^{2+}$, when the saccharide is transferred to protein there was a preferential disappearance of the $\mathrm{Glc}_{3}$-oligosaccharide. This is also shown in quantitative data (Fig. 5). The decrease in radioactivity in $\mathrm{Glc}_{3}$-oligosaccharide was compensated by a similar increase in glycoprotein. 
The Transfer of Glucose to a Dolichyl-DiphosphateGlucose-Containing Oligosaccharide Precursor. The formation of Dol-P-P-Glc-oligosaccharide has been, in most studies, carried out by incubating labelled UDP-Glc with microsomes. These provided an endogenous precursor believed to contain $\mathrm{Man}_{9} \mathrm{GlcNAc}_{2}$ joined to dolichyl diphosphate.

The addition of glucose to a precursor labelled in the mannose has been tested repeatedly in this laboratory but without clear results. Presumably there occurs a competition between UDP-Glc and GDP-Man for the Dol- $P$ available.

It was shown by Robbins et al. [16] that incubation of particulate enzyme preparation of fibroblasts with GDP- $\left[{ }^{14} \mathrm{C}\right]$ Man led to the formation of Dol-P-P oligosaccharides and that these became larger if UDPGlc was added in addition. The number of glucose added was not determined.

Experiments have now been carried out using an exogenous labelled acceptor. For this purpose liver microsomes were incubated with GDP- $-\left[{ }^{14} \mathrm{C}\right] \mathrm{Man}$ and the products having the solubility of Dol-P-P-Glc oligosaccharide were isolated. The major oligosaccharide formed was found to have a mobility slightly higher than the $\mathrm{Glc}_{1}$-oligosaccharide. As shown in Fig. 6 reincubation of the compound with microsomes and UDP-Glc led to the formation of a lipid linked oligosaccharide whose sugar moiety had the mobility of $\mathrm{Glc}_{3}$ and $\mathrm{Glc}_{2}$ oligosaccharides.

\section{DISCUSSION}

The solvent for paper chromatography described in this paper is nearly the same as the one used by Huber et al. [17] for thin-layer chromatography. It only differs in having slightly more water. With this solvent maltooligosaccharides of up to 16 units can be separated in 7 days. The neat separation of the different glucose-containing oligosaccharides has led to the clarification of several details of their transformations.

Although Dol- $P$ - $P$-Glc oligosaccharide was known to become labelled on incubation with radioactive Dol- $P$-Glc it remained to be proved if the three glucoses are introduced by the same mechanism. This has now been proved. As to the transfer of glucosecontaining oligosaccharide from its Dol- $P$ - $P$ derivative it had been detected long ago, but at that time the existence of compounds differing in glucose content was not known. It has now been found that only the oligosaccharide containing three glucoses is transferred to protein. If the dolichyl diphosphate derivatives of $\mathrm{Glc}_{2}$ and $\mathrm{Glc}_{1}$ oligosaccharides are also substrates, the process is so slow that it was not detectable in our experiments. The results complement those of Turco and Robbins [18] who isolated the glycopeptide formed immediately after transfer from Dol-P-P-Glc

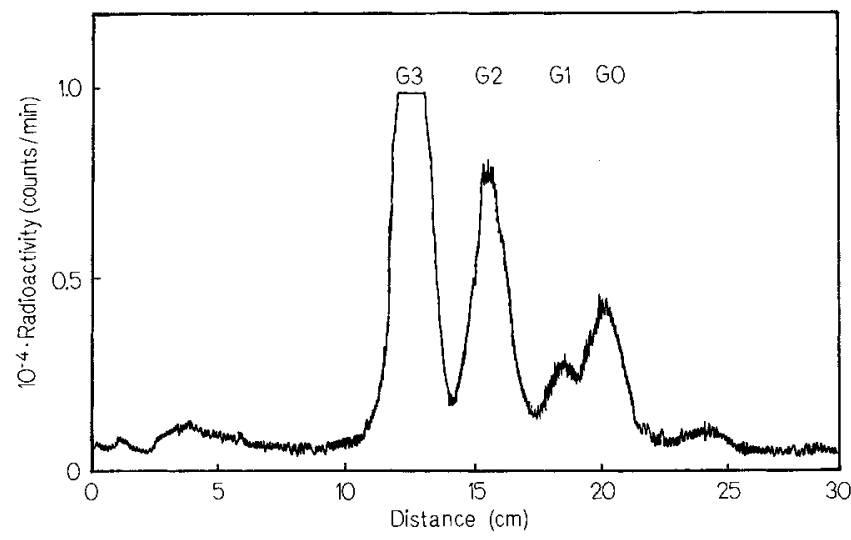

Fig. 3. Paper chromatography of oligosaccharides labelled in the glucose and mannose. The preparation was carried out with oviduct slices as described in $[9,10]$. Chromatography with the propanol/ nitromethane solvent for 7 days

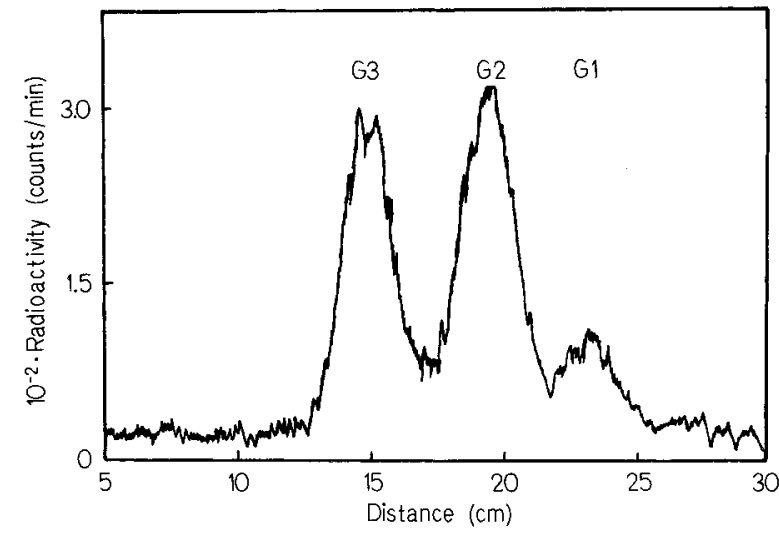

Fig. 4. Transfer of glucose from dolichyl phosphate $\left[{ }^{14} \mathrm{C} / g l u c o s e ~ t o\right.$ endogenous acceptors. The transfer reaction was carried out by

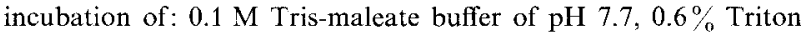
$\mathrm{X}-100,10 \mathrm{mM}$ Na-EDTA, $20 \mathrm{mM}$ 2-mercaptoethanol, Dol- $P$ $\left[{ }^{14} \mathrm{C}\right]$ Glc $(4000$ counts/min dried before the addition of the other components). Total volume $50 \mu \mathrm{l}$. After $10 \mathrm{~min}$ at $30^{\circ} \mathrm{C}$ chloroform and methanol were added and fractionation was carried out as described in [6]. The oligosaccharides obtained by mild acid hydrolysis were separated by paper chromatography with the solvent 1-butanol/pyridine/water $(4: 3: 4)$ for 20 days

oligosaccharide to protein and found that its size corresponded to the $\mathrm{Glc}_{3}$-containing compound. Transfer of mannose-labelled oligosaccharides presumably not containing glucose has been reported $[8,19]$. Their rate of transfer is slower and may involve endogenous glucose donors. Further work would be required in order to find out if the glucose-containing oligosaccharides are obligate intermediates in the glycosylation pathway.

The formation of Dol-P-P-Glc oligosaccharide has been carried out before by transfer from Dol- $P$-Glc to an endogenous acceptor present in the microsomal preparations [6]. In the experiments reported here an exogenous acceptor labelled in the mannose was prepared by incubation of liver microsomes with GDP $\left[{ }^{14} \mathrm{C}\right]$ Man followed by solvent extraction. In- 


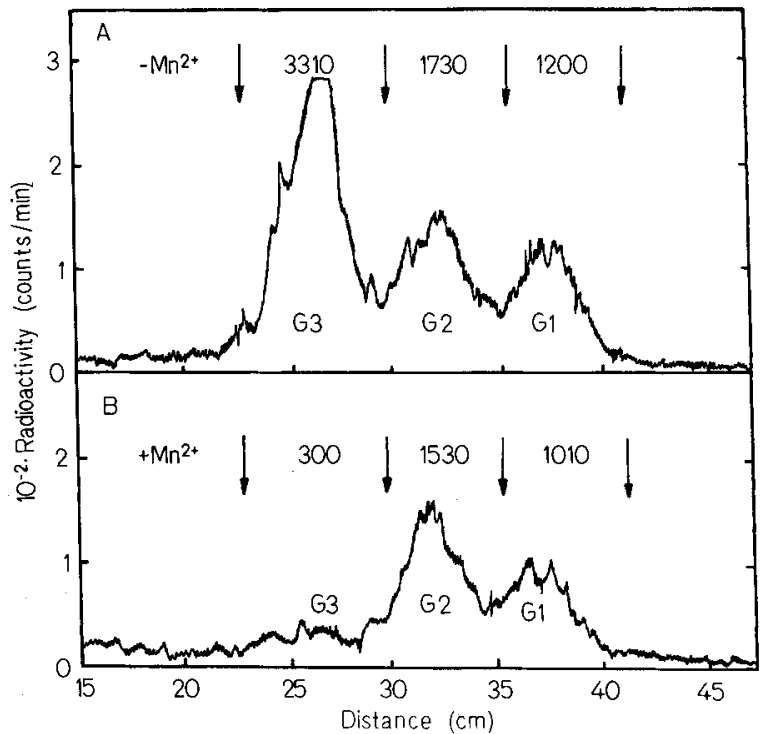

Fig. 5. Transfer of the glucose-containing oligosaccharides to protein. The Dol- $P$ - $P$-Glc-oligosaccharides ${ }^{14} \mathrm{C}$-labelled in the glucose (15000 counts $/ \mathrm{min}$ ) were dried and the following components were added: $80 \mathrm{mM}$ Tris-maleate buffer $(\mathrm{pH} \mathrm{7.7),2 \%}$ Triton X-100 and $10 \mathrm{mg}$ of microsomal protein in a total volume of $250 \mu \mathrm{l}$. Where indicated $8 \mathrm{mM} \mathrm{MnCl}_{2}$ was added. After $10 \mathrm{~min}$ at $30^{\circ} \mathrm{C}$ the mixture was processed as described in the legend of Fig. 2. The glucosecontaining oligosaccharides were chromatographed on paper and the protein precipitate was washed with methanol dissolved in $0.5 \mathrm{ml}$ of Protosol and counted by scintillation. The numbers indicate the radioactivity is counts/min in each peak. The radioactivity in the protein (in counts $/ \mathrm{min}$ ) was: minus $\mathrm{Mn}^{2+}: 900$, plus $\mathrm{Mn}^{2+}: 4500$. (A) No addition, (B) plus $\mathrm{Mn}^{2+}$

cubation of the compound with UDP-Glc led to the formation of Dol- $P$ - $P$-Glc oligosaccharides. The transfer of glucose to an exogenous acceptor had not been reported before. It is a necessary step for the study of the corresponding enzyme and may be useful in determining the structure of the glucose acceptor which is somewhat uncertain. Thus Hubbard and Robbins [20] presented evidence suggesting that it may contain eight and not nine mannose residues as would be expected.

The authors express their gratitude to Marcelo Tolmasky and Claudio Petriella for their valuable collaboration. R. S. is a career investigator of the Consejo Nacional de Investigaciones Cientificas $y$ Técnicas (Argentina).

\section{REFERENCES}

1. Staneloni, R. J. \& Leloir, L. F. (1978) Trends Biochem. Sci. $4,65-67$.

2. Parodi, A. J. \& Leloir, L. F. (1979) Biochim. Biophys. Acta, $559,1-37$.

3. Li, E., Tabas, I. \& Kornfeld, S. (1978) J. Biol. Chem. 253, $7762-7770$

4. Parodi, A. J., Behrens, N. H., Leloir, L. F. \& Carminatti, H. (1972) Proc. Natl Acad. Sci. U.S.A. 69, $3268-3272$.

5. Behrens, N. H. \& Leloir, L. F. (1970) Proc. Natl Acad. Sci. U.S.A. 66, 153-159.

6. Behrens, N. H., Parodi, A. J. \& Leloir, L. F. (1971) Proc. Natl Acad. Sci. U.S.A. 68, 2857-2860.

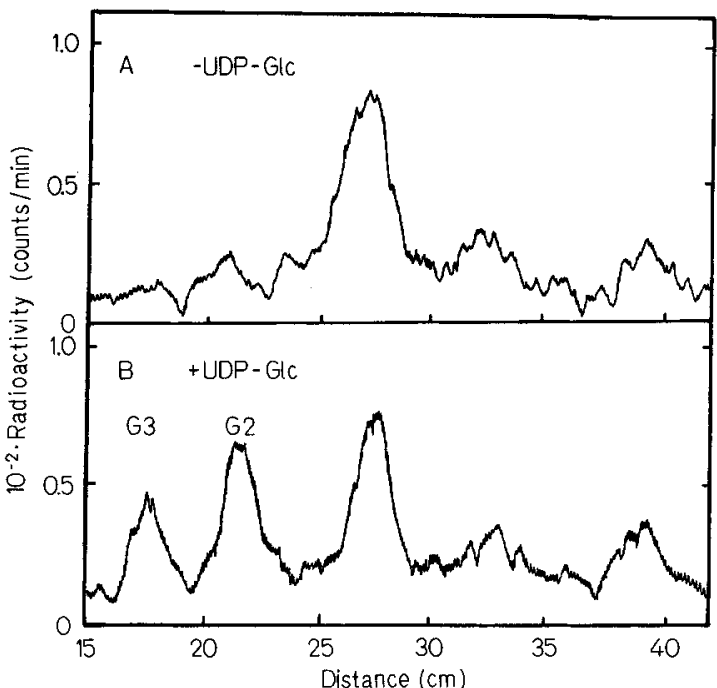

Fig.6. Transfer of glucose to a mannose-labelled exogenous acceptor. Dol- $P$ - $P$-oligosaccharide labelled in the mannose was prepared as described in [8]. A sample (5000 counts/min) was dried together with Dol- $P(10 \mu \mathrm{g})$. The following substances were then added $80 \mathrm{mM}$ Tris-maleate buffer (pH 7.7), $10 \mathrm{mM} \mathrm{Mg-EDTA,} 10 \mathrm{mM}$ $\mathrm{MgCl}_{2}, 0.1 \mathrm{M}$ 2-mercaptoethanol, $0.5 \%$ sodium deoxycholate and liver microsomes (about $2 \mathrm{mg}$ of protein). Total volume $50 \mu \mathrm{l}$. After $25 \mathrm{~min}$ at $30^{\circ} \mathrm{C}$ the products were processed for the preparation of the oligosaccharides and these were chromatographed with propanol/nitromethane solvent. (A) No addition; (B) plus $0.2 \mathrm{mM}$ UDP-Glc

7. Parodi, A. J., Staneloni, R. J., Cantarella, A. I., Leloir, L. F., Behrens, N. H., Carminatti, H. \& Levy, J. A. (1973) Carbohydr. Res. 26, 393-400.

8. Behrens, N. H., Carminatti, H., Staneloni, R. J., Leloir, L. F \& Cantarella, A. I. (1973) Proc. Natl Acad. Sci. U.S.A. 70 $3390-3394$

9. Spiro, M. J., Spiro, R. G. \& Bhoyroo, V. D. (1976) J. Biol. Chem. 251,6400-6408.

10. Staneloni, R. J. \& Leloir, L. F. (1978) Proc. Natl Acad. Sci U.S.A. $75,1162-1166$.

11. Kornfeld, S., Li, E. \& Tabas, I. (1978) J. Biol. Chem. 253 , $7771-7778$.

12. Ugalde, R. A., Staneloni, R. J. \& Leloir, L. F. (1978) FEBS Lett. 91, 209-212.

13. Spiro, M. J., Spiro, R. G. \& Bhoyroo, V. D. (1976) J. Biol. Chem. 25l, 6420-6425.

14. Ugalde, R. A., Staneloni, R. J. \& Leloir, L. F. (1979) Biochem. Biophys. Res. Commun. 91, 1174-1181.

15. Turco, S. J., Stetson, B. \& Robbins, P. W. (1977) Proc. Natl Acad. Sci. U.S.A. 74, $4411-4414$.

16. Robbins, P. W., Krag, S. S. \& Liu, T. (1977) J. Biol. Chem. $252,1780-1785$.

17. Huber, C. N., Scobell, H. D., Tai, H. \& Fisher, E. E. (1968) Anal. Chem. 40, 207-209.

18. Turco, S. J. \& Robbins, P. W. (1979) J. Biol. Chem. 254, $4560-4567$

19. Lucas, J. J., Waechter, C. J. \& Lennarz, W. J. (1975) J. Biol. Chem. 250, 1992-2002

20. Hubbard, S. C. \& Robbins, P. W. (1979) J. Biol. Chem. 254, $4568-4576$.

R. J. Staneloni, R. A. Ugalde, and L. F. Leloir, Instituto de Investigaciones Bioquímicas "Fundación Campomar",

Obligado 2490, RA-1428 Buenos Aires, Argentina 